\title{
En Defensa de una Epidemiología con Números
}

\author{
In Defense of a Quantitative \\ Epidemiology
}

En los últimos años, tanto en la epidemiología latinoamericana como en la anglosajona, abundan las críticas a la Ilamada epidemiología moderna, que ha predominado recientemente sobre todo en los Estados Unidos y que ha tenido enorme influencia sobre el desarrollo y el enfoque con el que se ha desarrollado la epidemiología en el resto del mundo. Las características más importantes de esta epidemiología son el énfasis en la medición y la cuantificación, y la obsesión con el uso de diseños de estudio y técnicas analíticas que permitan sacar conclusiones causales a partir de datos empíricos puramente observacionales. Es una epidemiología eminentemente cuantitativa, empírica y analítica. Este paradigma (en sentido kuhniano) epidemiológico queda plasmado en su máxima expresión en el tratado titulado Modern Epidemiology, de Rothman y Greenland, texto a menudo críptico, Ileno de fórmulas, centrado exclusivamente en problemas analíticos y con tendencia a transformar en problemas cuantitativos complejísimos ciertas cuestiones que durante décadas la epidemiología más tradicional trató de manera relativamente simple.

Sin duda, hay mucho que criticarle a esa epidemiología. Quizá una de las mayores críticas es que esa obsesión con el diseño de estudios y el análisis cuantitativo tienden a transformar la epidemiología en una disciplina puramente metodológica, muy cercana a la bioestadística y con escaso contenido teórico. La epidemiología queda reducida así a un conjunto de técnicas que, aparentemente, pueden aplicarse por igual para responder a cualquier problema empírico. Así, por ejemplo la llamada epidemiología clínica no es más que la aplicación de estas técnicas epidemiológicas a la investigación de preguntas relevantes a la práctica de la medicina. La epidemiología de los servicios de salud es la aplicación de estas técnicas para responder a preguntas relevantes para la organización, administración y prestación de servicios de salud. Por supuesto que es muy positivo que el desarrollo de la epidemiología haya traído rigor metodológico y capacidad de análisis objetivo a la práctica de la medicina y a la organización de servicios, dos áreas caracterizadas por muchas prácticas nunca sometidas a ningún tipo de evaluación para determinar su eficacia, o incluso para asegurar que no ocasionen más daños de los que intentan remediar. Pero al transformarse en un simple conjunto de métodos, la epidemiología como ciencia pierde la especificidad que la caracteriza. Esa especificidad que diferencia a la epidemiología de la clínica médica, por un lado, y de la sociología, por otro, es su objeto de estudio: los determinantes de la salud en las poblaciones. Este objeto de estudio tiene características propias que lo diferencian tanto de la fisiopatología sin componentes poblacionales o sociales, como de los fenómenos puramente sociales sin sustrato biológico. Al centrarse exclusivamente en cuestiones metodológicas, a veces a un nivel de abstracción extremo (como el mencionado libro de Rothman y Greenland), la epidemiología no solo se empobrece y se restringe, sino que también pierde capacidad para investigar, incluso desde el punto de vista cuantitativo, preguntas relacionadas con su objeto de estudio.

Dos correlatos de la creciente sofisticación metodológica de la epidemiología han sido la individualización y la biologización de su objeto de estudio. La individualización del objeto de estudio de la epidemiología se refiere al proceso por el cual la salud se concibe como un proceso definido exclusivamente a nivel de individuos, y cuyos determinantes se limitan a factores o procesos que ocurren 
exclusivamente a nivel individual. Con esta concepción, las poblaciones son de interés para la epidemiología no porque haya procesos a nivel poblacional que afecten la salud de los individuos que componen la población, sino porque el estudio estadístico de asociaciones requiere múltiples observaciones, es decir, grandes números o poblaciones de individuos. Estas poblaciones son simples cúmulos de individuos sin propiedades que se diferencien de las propiedades de los individuos que las componen. De ahí el gran énfasis de la llamada epidemiología moderna en los estudios a nivel individual, la medición sofisticada de características individuales y la gran preocupación por las limitaciones de los estudios ecológicos o de agregados (la famosa "falacia ecológica") para sacar conclusiones acerca de relaciones a nivel individual. La biologización (que a menudo acompaña a la individualización) es el proceso por el cual los determinantes de salud se conciben exclusivamente a nivel de características biológicas. De ahí la gran preocupación por la medición biológica y la desconfianza de la utilidad o de la importancia para la salud de las Ilamadas variables "blandas" sociales o culturales. La expresión más extrema de este proceso es el determinismo genético, cada vez más desprestigiado entre los propios genetistas a medida que avanza el conocimiento sobre el funcionamiento de los genes y de las múltiples maneras en que el genoma interactúa y se ve modificado en su expresión por el ambiente, no solo físico sino también social, en el que se encuentra el organismo.

Es importante destacar que la individualización y la biologización no son características sine qua non del abordaje cuantitativo de los problemas de salud. De hecho, es posible un abordaje cuantitativo que incorpore y contemple procesos y características poblacionales y sociales al investigar los determinantes de la salud y la enfermedad. Incluso puede argumentarse que el rigor científico a menudo requiere la contemplación de este tipo de factores, aunque la pregunta de investigación se formule puramente a nivel individual y biológico. Por ejemplo, la relación cuantitativa (o, en jerga epidemiológica, la asociación) entre un gen determinado y el riesgo de enfermedad a menudo difiere sustancialmente en función de la presencia de determinados factores ambientales (generalmente sociales o poblacionales, o condicionados por factores sociales o poblacionales) que interactúan con el gen y modifican su expresión, y por ende las consecuencias fisiopatológicas de la presencia de dicho gen.

El problema es que la crítica a ciertos aspectos de la epidemiología o, mejor dicho, a cierto tipo de epidemiología, se ha hecho equivalente, se ha transformado en una crítica a cualquier tipo de cuantificación o de análisis cuantitativo. Pero la individualización, la biologización, la descontextualización de los procesos de salud, críticas que se hacen a menudo a la epidemiología moderna, no son consecuencias necesarias de la cuantificación, si bien es verdad que a menudo estos procesos han ocurrido mano a mano. En su sentido más fundamental, la cuantificación no es más que una variante de la clasificación o la sistematización. La clasificación es parte no solo de las ciencias cuantitativas sino también de las cualitativas. Clasificar, sistematizar, sintetizar son componentes inherentes al proceso de abordaje científico de un problema. Por supuesto que no siempre captan el proceso en su totalidad, que tienen limitaciones, que a veces hay aspectos difíciles de clasificar o sistematizar, pero sin duda la clasificación o la cuantificación a menudo nos ayudan a entender mejor muchos aspectos de lo que estamos estudiando. Por supuesto que los números no lo dicen todo, pero este no es un error de los números sino de quien los interpreta, del que les atribuye erróneamente un significado que no tienen, del que pide peras al olmo. Tampoco puede sacarse todo de una serie de entrevistas en profundidad o de observaciones etnográficas. La inteligencia del investigador está en elegir la técnica más apropiada para lo que estudia, y en entender las ventajas y limitaciones del abordaje que elige. Pero para eso hay que conocer en profundidad la técnica que se utiliza. Por eso, a menudo suenan vacuas y simplistas las críticas a las técnicas cualitativas de los investigadores puramente cuantitativos y las críticas a los abordajes cuantitativos de los investigadores con formación puramente cualitativa.

Desde sus orígenes, quizás por sus raíces históricas en las estadísticas vitales y sociales y en la vigilancia y control de enfermedades, actividades que exigen sin remedio contar y tabular, la epidemiología ha sido una disciplina eminentemente cuantitativa, una disciplina para la cual los números son importantes. Desde luego que el objeto de estudio de la epidemiología, los determinantes de la salud y enfermedad en poblaciones, puede requerir abordajes complementarios cuantitativos y cualitativos. 
Que los abordajes cualitativos se incorporen a la epidemiología tradicional transformándola en una nueva epidemiología Ilamada epidemiología social o epidemiología sociocultural, o que simplemente signifique que los epidemiólogos (eminentemente cuantitativos) colaboren más a menudo con antropólogos, etnógrafos y sociólogos, es, en última instancia, una cuestión de forma y no de fondo. Sin duda, como se viene discutiendo desde hace décadas en las ciencias sociales, los abordajes cualitativos y cuantitativos son complementarios y la utilidad de cada uno depende del problema en cuestión. A menudo la interpretación de los resultados cuantitativos mejora si se tienen datos cualitativos que permitan contextualizar y entender mejor los procesos que los generaron. De la misma manera, los resultados cualitativos se contextualizan, y su relevancia y significación a menudo se destacan mejor si se complementan con datos cuantitativos.

Por su objeto de estudio, la epidemiología debe contemplar simultáneamente factores socioculturales y biológicos, así como factores individuales y poblacionales. Esto coloca a la epidemiología en un campo netamente transdisciplinario y le presenta una serie de retos tanto conceptuales o teóricos como metodológicos. También convierte a la epidemiología en un campo de investigación complejo y a menudo polémico, pero de gran interés no solamente desde el punto de vista puramente intelectual, sino también como herramienta que motive y contribuya a la acción y a la transformación de la realidad. Los números son parte inherente de esta epidemiología. No dejemos que la epidemiología se reduzca exclusivamente a ellos, pero aprendamos a diferenciar lo que los números revelan y esconden, y sobre todo, no dejemos de usarlos con rigor e inteligencia para ayudarnos a entender mejor la realidad que queremos transformar.

Ana V. Diez Roux

Profesora de Epidemiología

Center for Social Epidemiology and Population Health University of Michigan, Ann Arbor, EE.UU.

\section{FORMA DE CITAR}

Diez Roux AV. En defensa de una epidemiología con números. [Editorial]. Salud Colectiva. 2007;3(2):117-119. 